\title{
Transatlantica
}

Revue d'études américaines. American Studies Journal

\section{Pascale Antolin-Pires. Nathanael West : Poétique de} l'ecchymose.

Paris : Belin, 2002, 127 p.

\section{Anne Luyat}

\section{(2) OpenEdition}

\section{Journals}

Édition électronique

URL : http://journals.openedition.org/transatlantica/726

DOI : $10.4000 /$ transatlantica.726

ISSN : 1765-2766

Éditeur

AFEA

Référence électronique

Anne Luyat, «Pascale Antolin-Pires. Nathanael West : Poétique de l'ecchymose. », Transatlantica [En ligne], 1 | 2003, mis en ligne le 05 avril 2006, consulté le 29 avril 2021. URL : http://

journals.openedition.org/transatlantica/726 ; DOI : https://doi.org/10.4000/transatlantica.726

Ce document a été généré automatiquement le 29 avril 2021.

\section{c) (i) $\Theta$}

Transatlantica - Revue d'études américaines est mis à disposition selon les termes de la licence Creative Commons Attribution - Pas d'Utilisation Commerciale - Pas de Modification 4.0 International. 


\section{Pascale Antolin-Pires. Nathanael} West: Poétique de l'ecchymose.

Paris : Belin, 2002, 127 p.

Anne Luyat 
Rares sont les écrivains de l'entre-deux-guerres qui réussissent à Hollywood. Nathanael West est l'exception qui confirme la règle. Si, à la demande des studios tout puissants, il écrit des scénarios qui mettent en scène les chimères de la culture de masse, il se consacre dans ses romans et ses essais à la subversion de cette même culture. Pascale Antolin retrace avec précision le chemin qui mène le fils d'immigrés new-yorkais à construire une œuvre comique et sombre destinée à faire voler en éclats ces rêves frelatés. Nathanael West ne se contente pas de libérer les victimes de l'artifice médiatique, il s'applique simultanément à créer une esthétique que Pascale Antolin nomme avec bonheur la " poétique de l'ecchymose ". L'ecchymose ou tache noire produite par la diffusion du sang dans le tissu sous-cutané, soit à la suite d'un traumatisme, soit en rapport avec un trouble de la coagulation, traduit bien la conception qu'avait West d'une société malade à la fois de ses désirs absurdes et du simulacre.

L'analyse percutante de Mme Antolin, bien définie, présentée et annotée, situe le travail de West par rapport aux mouvements littéraires les plus importants, y compris la tradition juive de l'humour noir et le postmodernisme. Elle rappelle aussi l'influence d'écrivains tels que William Faulkner, William Steinbeck et Sherwood Anderson et ce faisant, l'importance de la tradition américaine du grotesque dans son œuvre. La comparaison avec Henri Bergson, plutôt inattendue, est convaincante et pourrait être approfondie, car c'est ici que se trouve la clé de l'énigme du fonctionnement du grotesque et donc, si l'hypothèse de Mme Antolin est bien posée, la base de la nouvelle esthétique de Nathanael West. Le livre est passionnant à lire en raison de la présentation détaillée de la fiction de West et parce qu'il indique la possibilité que nous avons d'examiner son écriture à travers les critiques modernes.

\section{INDEX}

Thèmes : Recensions

\section{AUTEUR}

\section{ANNE LUYAT}

Université d'Avignon 